\title{
Lipopolysaccharides: structure, function and bacterial identification ${ }^{\text {象, 败访 }}$
}

\author{
Martine Caroff ${ }^{1,2, *}$ and Alexey Novikov ${ }^{2}$ \\ ${ }^{1}$ LPS-BioSciences, Paris-Saclay University, 91400 Orsay, France \\ ${ }^{2}$ Hephaistos-Pharma, Paris-Saclay University, 91400 Orsay, France
}

Received 4 March 2020 - Accepted 11 May 2020

\begin{abstract}
Lipopolysaccharides (LPS) are the main components of the outer membrane of Gram-negative bacteria. They are glycolipids containing a lipid moiety called lipid A, more often made of a bisphosphorylated glucosamine disaccharide, carrying fatty acids in ester and amide linkages. Lipid A is linked to a core oligosaccharide of about 10 sugars, substituted in the wild-type strains, by long-chain oligosaccharide repetitive units, extending outside the bacteria and representing their main antigens. In addition to determine the serotype of the bacterium, LPS are highly potent biological molecules, capable of eliciting at the level of minute amounts, beneficial, as well as deleterious activities.
\end{abstract}

Keywords: lipopolysaccharide / endotoxins / inflammation / structure-activity / serology

Résumé - Lipopolysaccharides : structure, fonction et identification bactérienne. Les lipopolysaccharides (LPS) sont les composants majeurs de la membrane externe des bactéries à Gram négatif. Ce sont des glycolipides comprenant une région lipidique appelée lipide $\mathrm{A}$, le plus souvent faite d'un disaccharide de glucosamines phosphorylées et portant des acides gras en liaison ester ou amide. Le lipide A est lié à un core oligo-saccharidique d'à peu près dix sucres, substitué, pour les souches sauvages, par une longue chaîne faite d'unités d'oligosaccharides répétitifs qui s'étendent à l'extérieur de la bactérie et qui représentent leur antigène majeur. En plus de déterminer les sérotypes bactériens, les LPS sont des molécules hautement actives capable de déclencher à très faible dose des activités aussi bien bénéfiques que délétères.

Mots clés : lipopolysaccharide / endotoxines / inflammation / structure-activités / sérologie

\section{Introduction}

Lipopolysaccharides (LPS) are the molecular constituents of the so-called endotoxins. LPS are present in the outer leaflet of the external membrane of Gram-negative bacteria. Some examples of the latter are Escherichia coli, Salmonellae, other Enterobacteriaceae like Yersiniae or Shigellae, Enterobacter, Proteus, and pathogens like Vibrio cholerae, Yersinia pestis, Brucella abortus. A single E. coli cell is known to contain $2 \times 10^{6}$ LPS molecules, which corresponds to an amount of about 20 femtograms (Minabe et al., 1994).

LPS are made of three different regions (Fig. 1). The first one, a glycophosholipid moiety called lipid A, anchors LPS in the bacterial membrane, and is responsible for the majority of the biological effects of these potent molecules. Most of the

\footnotetext{
Contribution to the Topical Issue "Microbiota, Nutrition and Lipids: consequences on Health".

th This paper is dedicated to the memory of Dr Yvon LeBeyec, a dear friend and colleague.

* Corresponding author: martine.caroff@lpsbiosciences.com
}

time, lipid A moieties are linked to a core oligosaccharide, through an acidic deoxy sugar the 2-keto-3-deoxy-octulosonic acid (Kdo). The third moiety of LPS molecules, named the $\mathrm{O}$-chain, is made of oligosaccharide repeating units extending outside the bacteria. These $\mathrm{O}$-specific chain structures, being unique to a given bacterium, are at the origin of the serotyping, historically used to identify Gram-negative bacteria.

A certain number of important pathogens display LPS without O-chain, thus named lipooligosaccharide (LOS). Examples are Bordetella pertussis, Neisseria meningitidis, and Haemophilus influenzae.

LPS contributes to the outer membrane's integrity, it constitutes an efficient permeability barrier to antimicrobial compounds, and a protection against the complementmediated lysis thanks to the length of its O-chains. A good example of such protection was described in Shigella (West et al., 2005). Mutants showing Rough-type colonies on agar plates do not have O-chains in their LPS, they are more sensitive to the complement system and to antibiotics, than bacteria of the Smooth-type. The shortest LPS mutant structure is the deep-rough LPS type, it corresponds to a lipid A moiety 

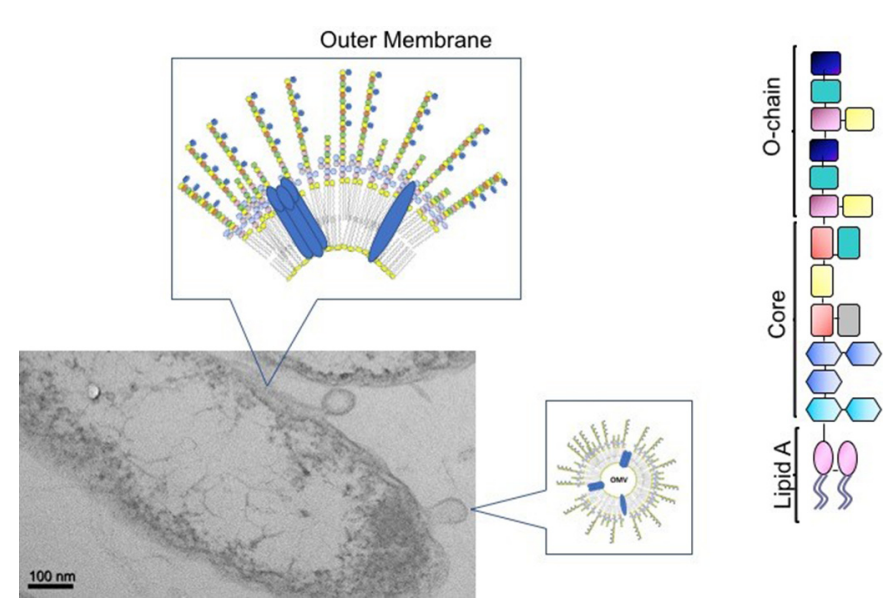

Fig. 1. Electron microscopy of a Ralstonia pickettii bacterium and schematic representation of the outer membrane of Gram-negative bacteria, outer membrane vesicles (OMV), and a LPS molecular species.

plus at least one Kdo molecule. Exceptions to the rule exist, and a mutant devoid of LPS has been described with $N$. meningitidis by insertional gene inactivation of the first step of LPS biosynthesis (Steeghs et al., 2001, 1998).

The bacterial viability was only possible when a capsular polysaccharide was present, and differences were observed in the phospholipids composition (Steeghs et al., 2001). Another example was described with Moraxella catarrhalis (Peng et al., 2005). Apart from these exceptions, in the large majority of cases, LPS is essential for bacterial survival like in case of E. coli.

\section{Lipopolysaccharide structures/function relationships, and bacterial detection}

In 1899 , R. Pfeiffer gave the name "endotoxins" by opposition to exotoxins because such toxins were not released by the bacteria-like proteins liberated in the course of the infectious process (Rietschel and Cavaillon, 2003). However, some LPS molecules get liberated during bacterial reproduction by fission of single cells, or when bacteria are killed, for example by use of antibiotics. If LPS get released in large amounts into the host blood, they can cause a massive inflammatory response and septic shock usually leading to main failure of most organs and death. When, on the contrary, LPS are present in small amounts, they stimulate the hostimmune response and can boost the immune system. These two drastically opposed reactions explain the constant interest of scientists for these amazing molecules.

\subsection{Structural analysis}

The main characteristic of LPS molecules is their capability to display a unique structure for a given bacterium. Being highly heterogeneous molecules in each of their three moieties, they necessitate complex and thorough analyses for their characterization. Such analyses are performed mainly by mass spectrometry (MS), nuclear magnetic resonance (NMR), liquid and gas chromatography-mass spectrometry (LC-MS and GC-MS), sodium dodecyl sulfate electrophoresis (SDSPAGE) and chemical analyses. We keep innovating in LPS structural analyses and already described major methods in the past decades, as summarized in Novikov et al. (2017).

\subsection{Lipid A structures}

One of the most described LPS structure is that of E. coli because it originates from an extensively studied bacterium. This is why non-specialists often extrapolate this structure as to "the" general one. To illustrate the real high variability of these molecules, some examples of lipid A structures varying among genera, and even in a single genus, are displayed in Figure 2. In most Enterobacteriacea, the lipid A structure corresponds to a bis-phosphorylated $\beta-1-6$ glucosamine disaccharide, carrying fatty acids (FA) in ester- and amide-linkages (Fig. 2).

Variability in the structure resides in the length of the FA aliphatic chains, as well as in the number of FA present on the disaccharide, varying from 2 to 9 . The phosphate groups are most often substituting glucosamine I (GlcN I) at C-1, and GlcN II at C4'. They are also at the origin of some variability, as they can be either present or absent, and substituted, or not, by amino-sugars (AraN, GlcN, GalN) or phosphoethanolamine (PEA), and other residues (like methyl-) often referred to as "decorations" (Novikov et al., 2014).

\subsection{Unusual lipid A structures}

While in the most widely described structures, lipid A is made of a GlcN disaccharide, other lipid A disaccharides were described with a 2,3-diamino-2,3-dideoxy-D-glucose (DAG) backbone, or with mixed compositions (Fig. 3).

A diaminoglucose disaccharide was found in structures such as those of Brucella, Legionella, Rhizobia and Ochrobactrum (Bundle et al., 1987; Caroff et al., 1984b; Lapaque et al., 2006; Mayer et al., 1989; Qureshi et al., 1994; Sonesson et al., 1989; Velasco et al., 1998; Zähringer et al., 1995). In some other cases, the disaccharide is a mixed structure with backbones composed of one DAG and one GlcN residues.

Campylobacter's lipid As were described as very complex structures as they contain a mixture of three types of disaccharide backbones: the classical di-GlcN, the di-DAG backbone and a mixture of GlcN-DAG disaccharide (Moran et al., 1991).

Other structures with lipids A containing GlcN or DAG disaccharide backbones were also described as being devoid of phosphate groups, like in the genus Rhodopseudomonas, growing in soil and aquatic media (Holst et al., 1983; Okamura et al., 2009).

The phototropic bacterium Rhodospirillum fulvum, with a classical lipid A di-GlcN backbone carries an unusual heptose residue at $\mathrm{C}-4$ ' and a galactosamine uronic (GalA) residue at C-1 (Rau et al., 1995).

Rhizobia lipid A have been described as non-phosphorylated lipids A carrying long-chain FA and their GlcN 1 residue is replaced by an acylated 2-aminogluconate (Mayer et al., 1989).

\subsection{Cores structures}

The core oligosaccharide is built up of a tens of monosaccharides arranged both in linear and branched structures. It consists of two distinct regions: the "inner core" proximal to the lipid A moiety, and the "outer core" to which 
M. Caroff and A. Novikov: OCL 2020, 27, 31
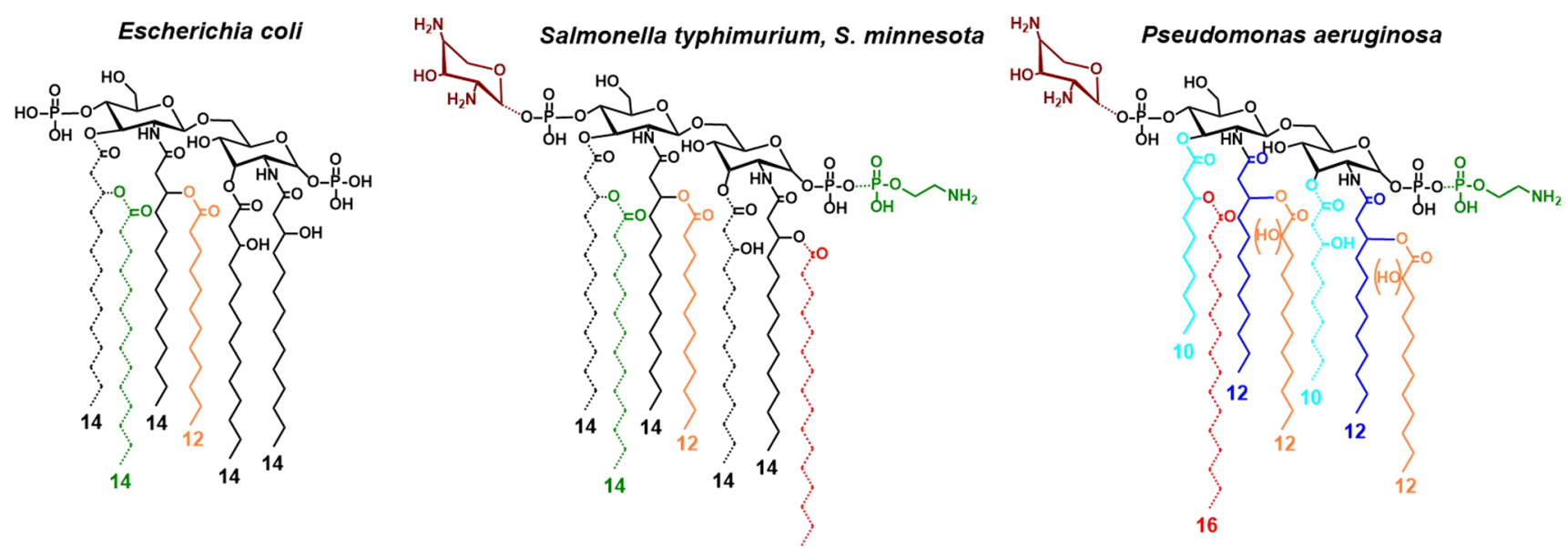

Bordetella pertussis

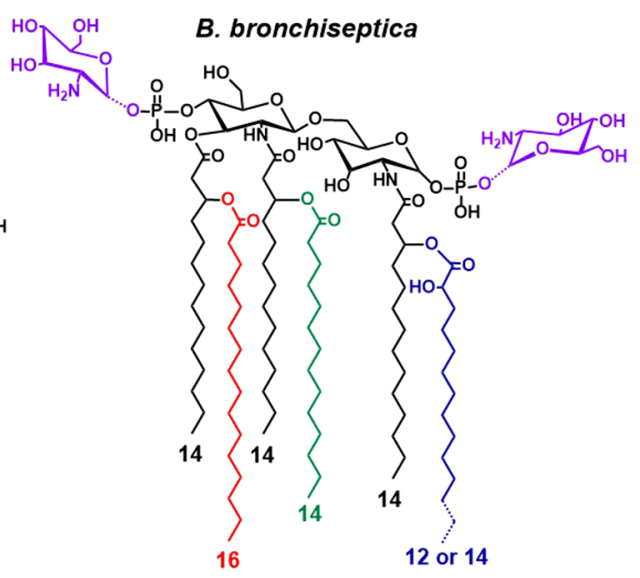

Fig. 2. Examples of lipid A structures.

Legionella pneumophila

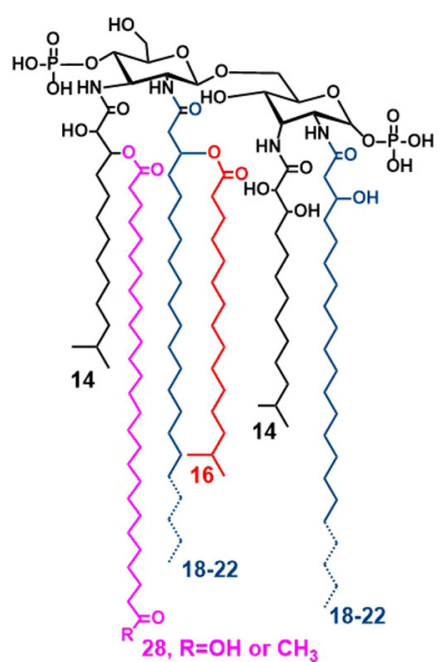

Fig. 3. Examples of unusual lipid A structures.

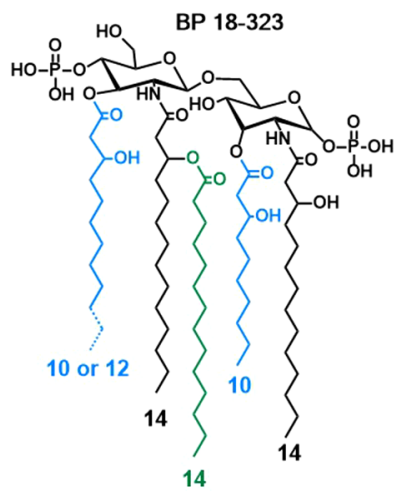

14 
the O-antigen can be linked (Holst, 2011). The inner-core structures usually represent the more conserved part of the core. In Enterobacteriaceae, cores are made of Kdo and Lglycero-D-manno-heptose residues (Hep). The first Kdo linked to the $O-6$ ' position of lipid A through an $\alpha$-ketosidic linkage is named Kdo-I, it can be substituted by one or two other Kdo residues (Kdo-II, and Kdo-III). Kdo-I is glycosylated at the $O$ 4 position by Hep, the first one designated as Hep-I, it can also be decorated by $\mathrm{P}$, or PEA or by one or two other Hep, or another sugar making the inner-core structure.

The enterobacterial "outer core" consists of an oligosaccharide of up to 6 sugars with Glc, Gal, GlcN, all in pyranose form, and in general displaying the $\alpha$-anomeric configuration (Caroff and Karibian, 2003). Figure 4 shows a few core examples like that of E. coli R3 core type, which is present in the serogroups O:157, O:111 and O:26 (Amor et al., 2000; Currie and Poxton, 1999).

The major modifications of $E$. coli core structures are most often made of nonstoichiometric additional Kdo, phosphate, PEA, rhamnose, and GlcN residues. It was shown that with PEA addition, originating from phosphatidylethanolamine, the bacterium becomes non-sensitive to antibiotics like polymixin and detergents (Yethon et al., 1998). Addition of positively charged groups like 4-AraN and PEA to the lipid A neutralizes the negative charges of its phosphate groups and prevents recognition and attachment of polymixin, a cationic antibiotic molecule.

Another gene specific to PEA addition was shown to be involved in $\mathrm{Ca}^{++}$hypersensitivity (Reynolds et al., 2005). The addition of PEA induced by high $\mathrm{Ca}^{++}$concentrations, protects bacteria from damages resulting from these high $\mathrm{Ca}^{++}$ concentrations. The molecular mechanism conferring this protection is not clear, but might be related to the capacity of PPEA to chelate multicharged $\mathrm{Ca}^{++}$ions.

The Pseudomonas aeruginosa core contains non-carbohydrate substituents such as P, PPEA, acetyl, carbamoyl residues and amino acids. P. aeruginosa also synthesizes two types of cores, one being caped and covalently linked to the O-chains, the second uncapped and devoid of O-chain (Lau et al., 2009).

\subsection{Lipooligosaccharide core structures}

As already mentioned, a number of highly virulent pathogens including B. pertussis, H. influenzae, N. meningitidis, and Campylobacter jejuni do not display an O-chain structure. Therefore, it is their complex and highly decorated core structures that are responsible for the bacterial specificity. The structure of H. influenzae and B.pertussis cores are depicted in Figure 4. The first one can be decorated, as indicated, by a glycine amino-acid substituent in various positions. This core also often carries phosphorylcholine residues (Post et al., 2016; Schweda et al., 2007). The B. pertussis core is composed of a first nonasaccharide core structure with unusual non-acylated amino groups at the two GlcNs and GalNA, and a distal trisaccharide originating from a different biosynthetic process. Effectively, this trisaccharide carries acetyl groups on each of the 4 amino groups of the highly immunogenic distal trisaccharide (Allen et al., 1998).

LOS vary with environment and culture conditions, their cores are often longer than usual cores and can extend up to
15 sugars. In non-typable $H$. influenzae (NTHi), a distal Kdo or Neu5Ac could be added to the distal part of the structure on $\mathrm{N}$ acetyllactosamine (Apicella et al., 2018).

\subsection{O-chains structures}

O-chains are known as the most variable structures in LPS molecules, and one cannot find two identical LPS structures for two different bacteria. If a very little number of identical Ochain structures were described, like with B.abortus and Yersinia enterocolitica O:9 (Caroff et al., 1984a, 1984b), their lipid A moiety and core structures remain different which makes different LPS structures in the end. In the great majority of cases, the O-chain structures can be compared to fingerprints, due to their uniqueness.

The repeating units of O-chains are typically made of oligosaccharides of 1 to 8 sugars. They are linear or branched structures and contain substituents like phosphate groups, Oacetyl groups, glycerol, ribitol, etc. The wide range of linkages between two consecutive sugars explains the high diversity of these structures. If there is only one possibility to form an amino-acid homodimer, there are 11 possibilities when it comes to a hexose disaccharide, due to the number of hydroxyl groups and stereo specificity of sugars, as well as to their anomeric linkage. Therefore, if there is again only one possibility for assembling a homotrimer amino-acid, there are 176 possibilities when it comes to hexoses, and 6 possibilities for an hetero-trimer amino-acid, compared to 1056 possibilities with three different hexoses. In fact, the number of existing combinations is reduced, due to specificity of biosynthetic enzymes. It remains however by far higher, compared to any other type of biomolecules. The number of combinations when it comes to sugars explain the complexity and diversity of polysaccharide structures.

Some examples of O-chain structures are displayed on Figure 5 .

\section{Lipopolysaccharides biosynthesis}

LPS biosynthetic processes have well been described by Raetz et al. and for E. coli they are known as the "Raetz pathway" (Raetz, 1990; Raetz and Whitfield, 2002). The lipid A biosynthetic enzymes were also well described by Trent et al. in 2004 (Trent, 2004; Trent et al., 2006). The complete LPS biosynthesis pathway starts with the lipid A-Kdo 2 moiety molecule, which is first synthesized at the surface of the cytoplasmic membrane. The other core sugars are added to $\mathrm{Kdo}$, into the inner membrane, before the lipid A-core molecules get flipped into the periplasmic space of the cytoplasmic membrane thanks to MsbA. The O-antigen is then synthesized by cytoplasmic membrane-associated enzyme complexes using C55 undecaprenyl-P as an acceptor for chain assembly, and is itself flipped into the periplasmic space of the membrane by one of the three following systems embedded into the outer membrane: Wzy dependent, ABC transporter dependent and synthase dependent (Valvano et al., 2011).

LPS molecules display highly diverse structures and high heterogeneity after their biosynthesis at the level of the cytoplasmic membrane surface due to a large number of enzymatic steps which can be consecutive or parallel, 
A. Escherichia coli R3

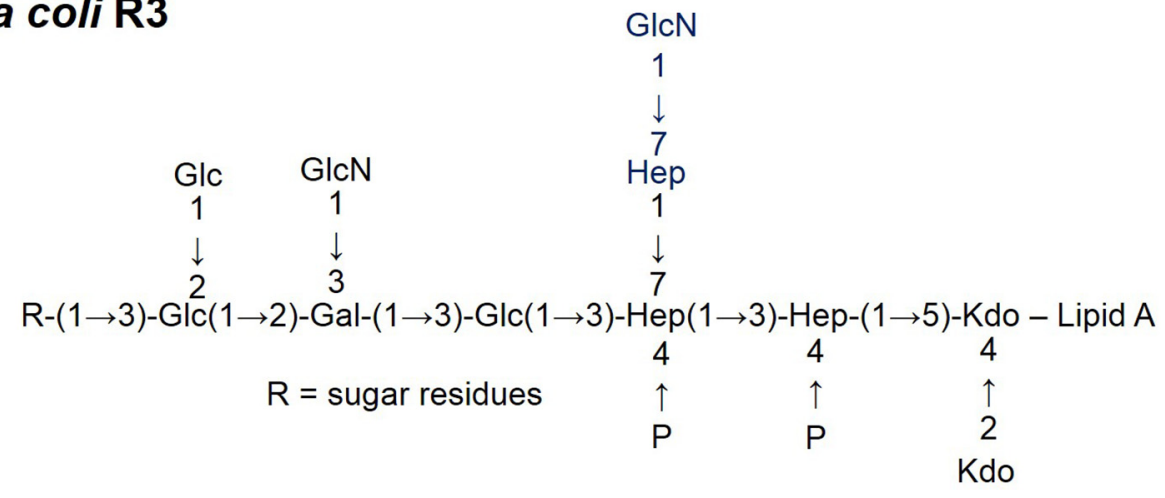

B. Bordetella pertussis

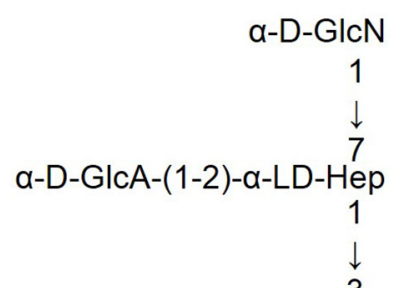

R-(1-6)- $\alpha-D-G|c N-(1-4)-\beta-D-G| c-(1-4)-\alpha-L D-H \stackrel{3}{\text { ep }}-(1-5)-\alpha-K d o$ - Lipid A

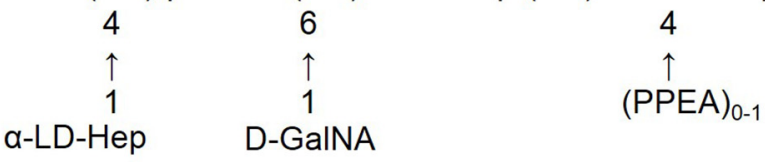

$R=\alpha-D-G I c N A c-(1-4)-\beta-D-M a n 2 N A c A-(1-3)-\beta-L-2 N A c, 4 N M e F u c-(1-$

C. Haemophilus influenzae

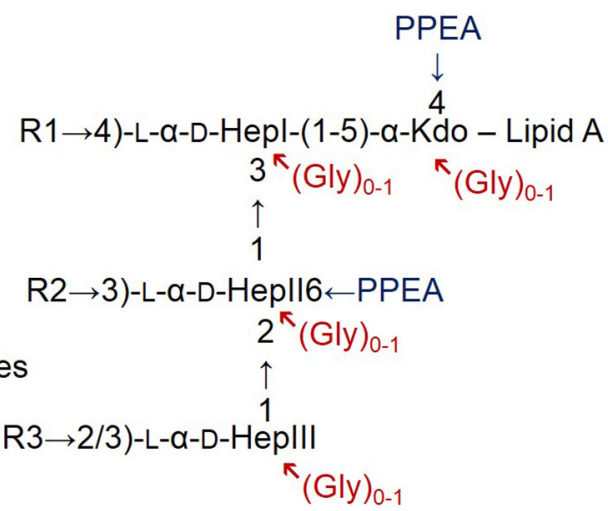

D. Pseudomonas aeruginosa

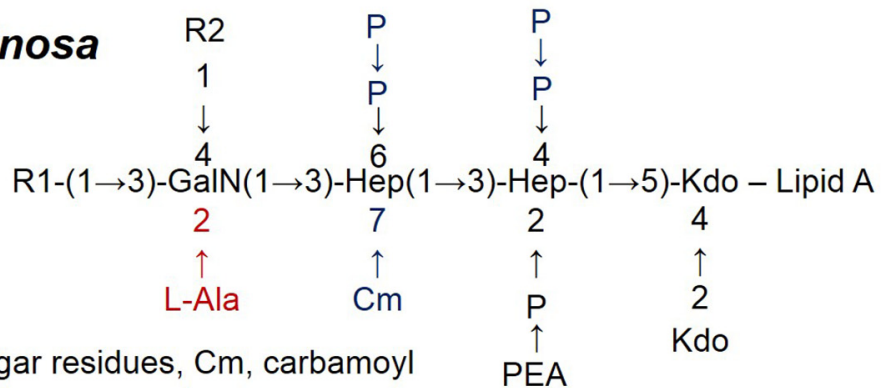

Fig. 4. Examples of core structures. 


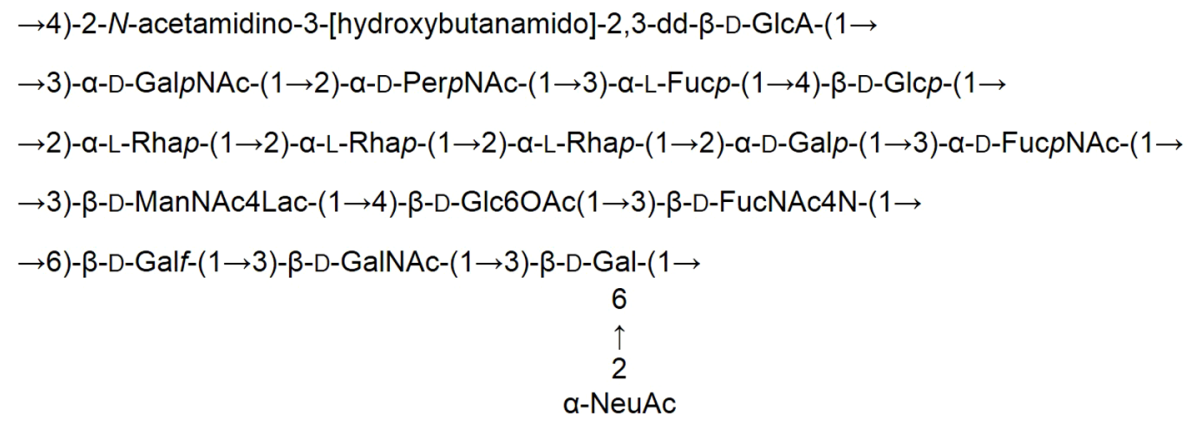

Bordetella avium ATCC5086

Escherichia coli O157:H7

Enterobacter cloacae C4115

Fusobacterium nucleatum MJR 7757B

Hafnia alvei 10457

Fig. 5. Examples of O-chain structures.

independent or competing. The late stages of the biosynthesis, known as post-translational biosynthesis modifications, are adding lots of heterogeneity to these already heterogeneous molecules. These modifications are operated by enzymes often regulated via two component regulators (e.g. PhoP-PhoQ) in response to stress (Delgado et al., 2006; Groisman, 2001; Gunn, 2001; Richards et al., 2010). This provides to bacteria a powerful and flexible mechanism of adaptation to the environment, as well as to modifications of the growth conditions when it comes to planktonic cultures. Such modifications are for example the addition of FA like 16:0, or the removal of some of the FA added during the constitutive biosynthesis process in the cytoplasm. These modifications take place when the entire LPS molecule is already inserted in the outer membrane and the added palmitate residues originate from other bacterial components such as phospholipids (PPL) or lipoproteins. Other late-steps structural modifications consist in addition of AraN, GlcN, GalN or PEA on the phosphate groups of lipid A. These "decorations" take place in the periplasmic space during transport of LPS molecules from the outer surface of the cytoplasmic membrane to the inner surface of the outer membrane (Shah et al., 2013).

Multiple structural lipid A modifications in the same pathogens, induced by changing of bacterial lifestyle from planktonic culture to biofilm conditions were demonstrated by Chalabaev et al. (2014) and Ciornei et al. (2010). These main examples show how imprudent it could be to trust laboratory growth conditions, for representing natural highly variable growth conditions, especially at the level of LPS structures easily modified according to niches and environment.

\section{Lipopolysaccharides and metabolic diseases}

A lot of attention has recently been given to the intestinal microbiome and its impact on health (Garidou et al., 2015; Kamada et al., 2013; Zhang-Sun et al., 2015). There are 100 trillions microorganisms in the microbiota, namely bacteria, viruses, archaea, and eukaryotes (Thursby and Juge, 2017). They participate to the immune system maturation, help against pathogens, and secrete useful vitamins.

It was shown that an increase in Gram-negative bacteria occurred in obese patients as well as in rich-diet mouse models. An increase in low-inflammatory LPS amount in the blood of patients with such metabolic diseases could explain the observed reaction leading to impact the insulin receptor (Cani et al., 2007).
The presence of Ralstonia has been demonstrated to increase in patients with metabolic diseases, we thus characterized the lipid A structures of three different species from this genus (Zhang-Sun et al., 2018). The hypo-acylated penta-acyl Ralstonia picketti lipid A structure, together with the decoration with AraN on both phosphate groups, was characterized. Both substitution with AraN and underacylation are known to favor the liberation of blebs, also called outer membrane vesicles (OMV), from the bacterial membrane (Elhenawy et al., 2016). We also showed by electron microscopy (Fig. 6) that the thickness of the bacterial membrane varied with LPS structures, and that the short LPS of $R$. pickettii, together with its lipid A under-acylation and phosphate groups decorations was generating more blebs from its thin membrane. These blebs cross the intestinal membrane more easily than bacteria can do, and deliver more LPS to the blood. However, the characterized structure was shown to induce low levels of cytokines, if any, as shown in Figure 6, which was also in adequation with the low-grade inflammation level described in obese patients. This represents a new example of low inflammatory capacities of LPS originating from the intestinal microbiome, explaining that these LPS were not as toxic and dangerous as the E.coli type classical structures. Other examples were published by d'Hennezel et al. (2017) concerning the deacylated structure of bacteroidales LPS, originating from the human microbiome and their silenced Toll-like signaling capacity, explaining hosttolerance to the gut LPS microbiome.

\section{Lipopolysaccharides detection methods}

\subsection{Limulus amoebocyte lysate}

The capacity to detect endotoxins in drugs is essential, as these molecules, when toxic, are known to lead to septic shock and death when present in the blood at low concentrations. The international pharmacopea have imposed the limulus amoebocyte lysate (LAL) tests for LPS detection. Limulus polyphemus, the horseshoe crab lymph, is used to detect femtograms of LPS in pharmaceuticals, parenteral, implants... In this crab, as in other arthropods and mollusks, the oxygen transport relies on a copper-based pigment, hemocyanin giving a blue color to the lymph. The presence of LPS results in lymph coagulation and different tests have been set up since the 1970s. LAL is recognized as one of the most sensitive detection method, but other gel-clot, turbidimetric and chromogenic assays have been developed since the first test 


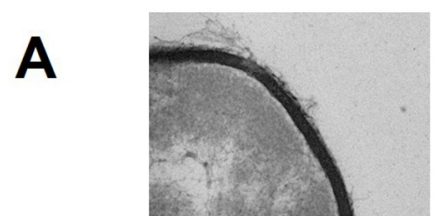

R. eutropha

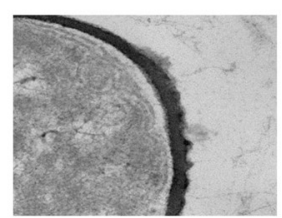

R. mannitolilytica

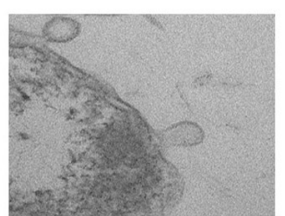

R. picketii
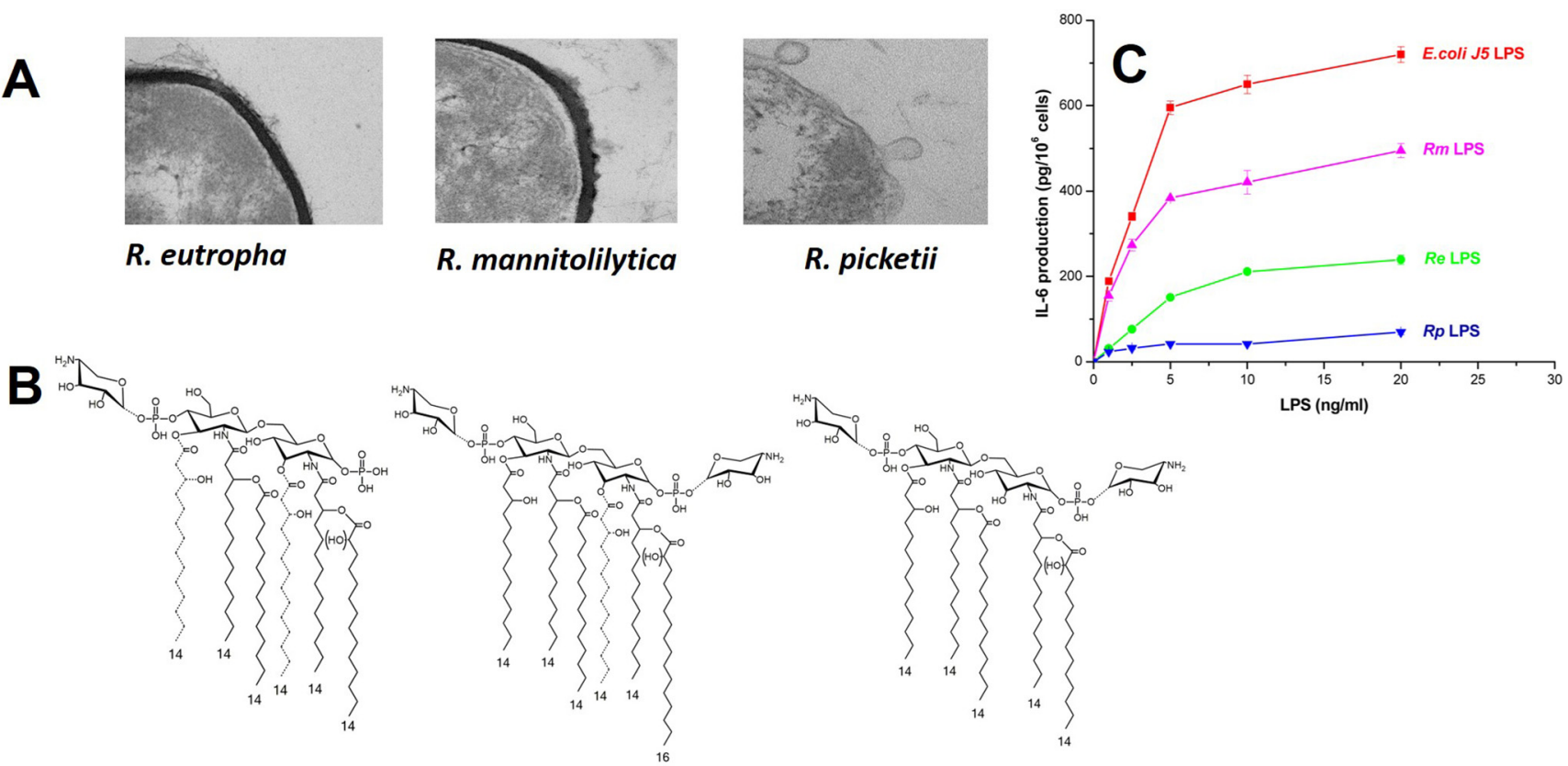

Fig. 6. (A) Electron microscopy showing the membrane thickness of three different Ralstonia species together with (B) their lipid A structures (Re: R. eutropha; Rm: R. mannitolilytica; Rp: R. pickettii), and (C) comparison of their LPS IL-6 inducing capacities.

was developed. The method used in pharmaceuticals was also used to detect the presence of heat stable endotoxin (LPS) in powdered infant milk (Townsend et al., 2007).

However, some glucans, proteins, blood factors and exotoxins can interfere with the test, and $\mathrm{pH}$ temperature, and ionic strength can influence the detection. A phenomenon called low endotoxin recovery (LER) disrupts LPS detection, it is thoroughly described in "Endotoxin Detection and Control in Pharma, Limulus, and Mammalian Systems | SpringerLink" (n.d.).

In order to protect the horseshoe crab, an alternative has been introduced with use of factor $\mathrm{C}$, a lysate protein produced to replace the crab lymph. Its sensitivity reaches $0.001 \mathrm{EU} / \mathrm{ml}$. It also allows overcoming interferences of certain factors but does not seem to be a panacea.

\subsection{Liquid chromatography-mass spectromtry (LC-MS2)}

Detection of FA markers, the famous 3-OH FA, specific to Gram-negative bacteria, has been developed to estimate an equivalent amount of endotoxin, based on E. coli used as a standard. It is less sensitive than LAL, but less prone to interferences and can be used for detection in blood.

\subsection{Serological and structural detection}

Bacterial detection kits can be prepared for Elisa tests as described in Sippel et al. (1987). Such kits or strips can also be used to detect the presence of food borne bacteria in stocks of crops (Bruno, 2014).

Due to their main characteristics as unique structures representing a given species, LPS are precious tools for bacterial detection and characterization. Mass spectrometry detection methods can be used to characterize specific LPS structures. Lipid A structures are characteristic of a given bacterial genus, and can be used as phylogenic tools. On the other hand, the O-chain structures are specific of a single bacterial species and are thus useful to detect a specific bacterium.

\subsubsection{Antibodies}

LPS can be used to prepare antibodies, used for bacterial detection with a high specificity and sensitivity. The use of LPS antibodies has been performed for defining bacterial serology long before the O-chain structures could be characterized. Anne-Marie Staub, from the Pasteur Institute, established the polysaccharide nature of bacterial O-antigens (Staub and Tinelli, 1956). In collaboration with the German researchers, Otto Westphal and Otto Lüderitz, they demonstrated that repeating units of one to 10 sugars formed the LPS speciesspecific O-antigens (Staub et al., 1959).

Numerous tests based on LPS detection to assess bacterial presence were set up in the past decades. They were used in Elisa and strip tests (Wang et al., 2011).

\subsubsection{Matrix assisted laser desorption mass spectrometry (MALDI-MS)}

LPS detection through its lipid A MALDI-MS analysis was recently improved in terms of sensitivity. It can be used at the same time to characterize LPS, and to get information on the bacterial genera.

We have ourselves defined a good level of sensitivity by detecting in MALDI-MS molecular ions corresponding to the E. coli lipid A moiety at $\mathrm{m} / \mathrm{z} 1797$, using serial dilutions of bacterial cultures and not dilution of a final concentrated lipid A extract. This method can be used to characterize the origin of the detected LPS, as well as the capacity of the bacterium to 


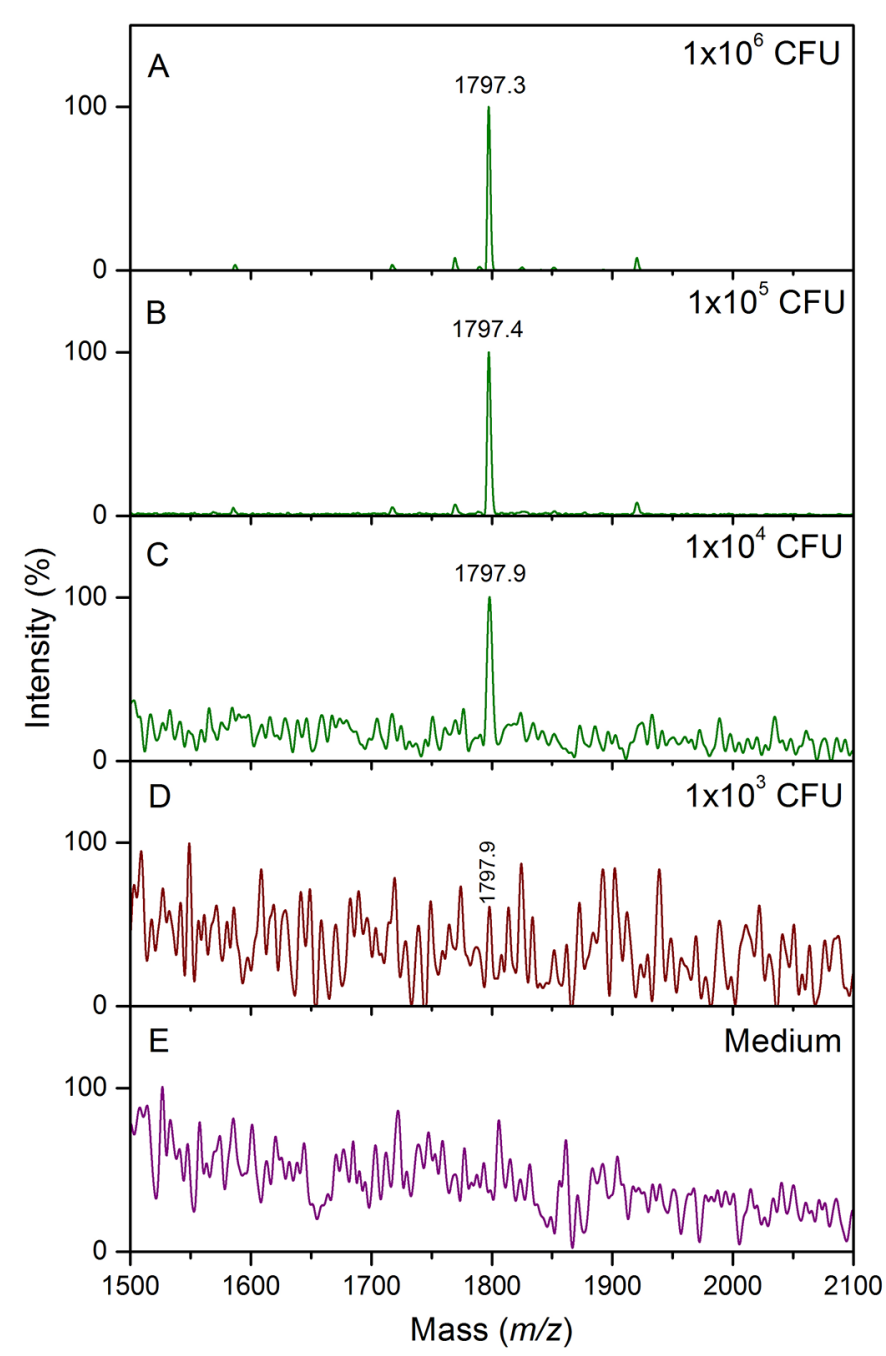

Fig. 7. Maldi-MS detection of a E. coli lipid A characteristic ion at $\mathrm{m} /$ $z 1797$ in a $1 \mathrm{ml}$ bacterial culture sample containing a total number of bacterial cells as low as $1 \times 10^{3}-1 \times 10^{4} \mathrm{CFU}$.

resist to polymixin according to the presence or absence of decorations on the lipid A phosphate groups.

The results are presented in Figure 7 and show that a characteristic peak can be obtained from a $1 \mathrm{ml}$ bacterial culture sample containing a total number of bacterial cells as low as $1 \times 10^{3}-1 \times 10^{4} \mathrm{CFU}$. Comparable experiments published by other authors gave detection limit of $1 \times 10^{5} \mathrm{CFU}$ (Leung et al., 2017).

All three described methods should be considered when LPS detection is vital, like in the medical and pharmaceutical domains. When interferences occur, one method can compensate the others, and use of at least two complementary methods is highly recommended.

\section{Conclusion}

LPS are amazing ubiquitous molecules, they are tracked down to avoid their presence in pharmaceuticals, or passage to the blood during infection, potentially leading to septic shock.
On the other hand, the capacity of these molecules to stimulate the immune systems at low doses, or by use of detoxified molecules, opens a broad field of applications in the domain of vaccination and immunotherapy. If genomic studies helped understanding the biosynthetic pathways leading to LPS structures, the post-translational modifications happening after LPS transfer to the external membrane is difficult to predict and necessitates complex structural analysis methods and tools. A unique LPS structure corresponding to a given species or even a strain, the number of already characterized structures is therefore limited. The influence of LPS molecules, and their structures, in the human intestinal microbiome is a good example of the importance of these key molecules on health in recent developments. According to the current incapability to grow most existing bacteria, major discoveries, and developments, are still expected in the LPS domain.

Conflicts of interest. The authors declare that they have no conflicts of interest in relation to this article.

\section{References}

Allen AG, Isobe T, Maskell DJ. 1998. Identification and Cloning of waaF (rfaF) from Bordetella pertussis and use to generate mutants of Bordetella spp. with deep rough lipopolysaccharide. $J$ Bacteriol 180: 35-40.

Amor K, Heinrichs DE, Frirdich E, Ziebell K, Johnson RP, Whitfield C. 2000. Distribution of core oligosaccharide types in lipopolysaccharides from Escherichia coli. Infect Immun 68: 1116-1124.

Apicella MA, Coffin J, Ketterer M, et al. 2018. Nontypeable Haemophilus influenzae lipooligosaccharide expresses a terminal ketodeoxyoctanoate in vivo, which can be used as a target for bactericidal antibody. mBio 9: e01401-e01418. Available from https://doi.org/10.1128/mBio.01401-18.

Bruno JG. 2014. Application of DNA aptamers and quantum dots to lateral flow test strips for detection of foodborne pathogens with improved sensitivity versus colloidal gold. Pathogens 3: 341355. Available from https://doi.org/10.3390/pathogens3020341.

Bundle DR, Cherwonogrodzky JW, Caroff M, Perry MB. 1987. The lipopolysaccharides of Brucella abortus and B. melitensis. Ann Inst Pasteur Microbiol 138: 92-98.

Cani PD, Amar J, Iglesias MA, et al. 2007. Metabolic endotoxemia initiates obesity and insulin resistance. Diabetes 56: 1761-1772. Available from https://doi.org/10.2337/db06-1491.

Caroff M, Bundle DR, Perry MB. 1984a. Structure of the O-chain of the phenol-phase soluble cellular lipopolysaccharide of Yersinia enterocolitica serotype O:9. Eur J Biochem 139: 195-200.

Caroff M, Bundle DR, Perry MB, Cherwonogrodzky JW, Duncan JR. 1984b. Antigenic S-type lipopolysaccharide of Brucella abortus 1119-3. Infect Immun 46: 384-388.

Caroff M, Karibian D. 2003. Structure of bacterial lipopolysaccharides. Carbohydr Res 338: 2431-2447.

Chalabaev S, Chauhan A, Novikov A, et al. 2014. Biofilms formed by Gram-negative bacteria undergo increased lipid a palmitoylation, enhancing in vivo survival. mBio 5: e01116-e01114. Available from https://doi.org/10.1128/mBio.01116-14.

Ciornei CD, Novikov A, Beloin C, et al. 2010. Biofilm-forming Pseudomonas aeruginosa bacteria undergo lipopolysaccharide structural modifications and induce enhanced inflammatory cytokine response in human monocytes. Innate Immun 16: 
288-301. Available from https://doi.org/10.1177/ 1753425909341807.

Currie CG, Poxton IR. 1999. The lipopolysaccharide core type of Escherichia coli O157:H7 and other non-O157 verotoxinproducing E. coli. FEMS Immunol Med Microbiol 24: 57-62. Available from https://doi.org/10.1111/j.1574-695X.1999. tb01265.x.

d'Hennezel E, Abubucker S, Murphy LO, Cullen TW. 2017. Total lipopolysaccharide from the human gut microbiome silences tolllike receptor signaling. mSystems 2: e00046-17. Available from /msystems/2/6/msys.00046-17.atom, https://doi.org/10.1128/ mSystems.00046-17.

Delgado MA, Mouslim C, Groisman EA. 2006. The PmrA/PmrB and RcsC/YojN/RcsB systems control expression of the Salmonella O-antigen chain length determinant. Mol Microbiol 60: 39-50. Available from https://doi.org/10.1111/ j.1365-2958.2006.05069.x.

Elhenawy W, Bording-Jorgensen M, Valguarnera E, Haurat MF, Wine E, Feldman MF. 2016. LPS remodeling triggers formation of outer membrane vesicles in Salmonella. mBio 7. Available from https://doi.org/10.1128/mBio.00940-16.

Endotoxin Detection and Control in Pharma, Limulus, and Mammalian Systems | SpringerLink [WWW Document], n.d. Available from https://link.springer.com/book/10.1007/978-3030-17148-3 (accessed 2.29.20).

Garidou L, Pomié C, Klopp P, et al. 2015. The gut microbiota regulates intestinal CD4 T cells expressing ROR $y$ t and controls metabolic disease. Cell Metab 22: 100-112. Available from https://doi.org/10.1016/j.cmet.2015.06.001.

Groisman EA. 2001. The pleiotropic two-component regulatory system PhoP-PhoQ. J Bacteriol 183: 1835-1842. Available from https://doi.org/10.1128/JB.183.6.1835-1842.2001.

Gunn JS. 2001. Bacterial modification of LPS and resistance to antimicrobial peptides. J Endotoxin Res 7: 57-62.

Holst O. 2011. Structure of the lipopolysaccharide core region. In: Bacterial lipopolysaccharides. pp. 21-39. Available from https:// doi.org/10.1007/978-3-7091-0733-1_2.

Holst O, Borowiak D, Weckesser J, Mayer H. 1983. Structural studies on the phosphate-free lipid A of Rhodomicrobium vannielii ATCC 17100. Eur J Biochem 137: 325-332. Available from https://doi. org/10.1111/j.1432-1033.1983.tb07832.x.

Kamada N, Chen GY, Inohara N, Núñez G. 2013. Control of pathogens and pathobionts by the gut microbiota. Nat Immunol 14: 685-690. Available from https://doi.org/10.1038/ni.2608.

Lapaque N, Forquet F, Chastellier CD, et al. 2006. Characterization of Brucella abortus lipopolysaccharide macrodomains as mega rafts. Cell Microbiol 8: 197-206. Available from https://doi.org/ 10.1111/j.1462-5822.2005.00609.x.

Lau PCY, Lindhout T, Beveridge TJ, Dutcher JR, Lam JS. 2009. Differential lipopolysaccharide core capping leads to quantitative and correlated modifications of mechanical and structural properties in Pseudomonas aeruginosa biofilms. J Bacteriol 191: 6618-6631. Available from https://doi.org/10.1128/ JB.00698-09.

Leung LM, Fondrie WE, Doi Y, et al. 2017. Identification of the ESKAPE pathogens by mass spectrometric analysis of microbial membrane glycolipids. Sci Rep 7. Available from https://doi.org/ 10.1038/s41598-017-04793-4.

Mayer H, Krauss JH, Urbanik-Sypniewska T, Puvanesarajah V, Stacey G, Auling G. 1989. Lipid A with 2, 3-diamino-2, 3dideoxy-glucose in lipopolysaccharides from slow-growing members of Rhizobiaceae and from "Pseudomonas carboxydo- vorans". Arch Microbiol 151: 111-116. Available from https:// doi.org/10.1007/bf00414423.

Minabe M, Takeuchi K, Kumada H, Umemoto T. 1994. The effect of root conditioning with minocycline $\mathrm{HCl}$ in removing endotoxin from the roots of periodontally-involved teeth. J Periodontol 65: 387-392. Available from https://doi.org/10.1902/ jop.1994.65.5.387.

Moran AP, Zähringer U, Seydel U, Scholz D, Stütz P, Rietschel ET. 1991. Structural analysis of the lipid A component of Campylobacter jejuni CCUG 10936 (serotype O:2) lipopolysaccharide. Description of a lipid A containing a hybrid backbone of 2-amino2-deoxy-D-glucose and 2, 3-diamino-2, 3-dideoxy-D-glucose. Eur J Biochem 198: 459-469.

Novikov A, Breton A, Caroff M. 2017. Micromethods for isolation and structural characterization of lipid A, and polysaccharide regions of bacterial lipopolysaccharides. Methods Mol Biol 1600: 167-186. Available from https://doi.org/10.1007/ 978-1-4939-6958-6_16.

Novikov A, Shah NR, AlBitar-Nehme S, et al. 2014. Complete Bordetella avium, Bordetella hinzii and Bordetella trematum lipid A structures and genomic sequence analyses of the loci involved in their modifications. Innate Immun 20: 659-672. Available from https://doi.org/10.1177/1753425913506950.

Okamura K, Takata K, Hiraishi A. 2009. Intrageneric relationships of members of the genus Rhodopseudomonas. J Gen Appl Microbiol 55: 469-478. Available from https://doi.org/10.2323/ jgam.55.469.

Peng D, Hong W, Choudhury BP, Carlson RW, Gu X-X. 2005. Moraxella catarrhalis bacterium without endotoxin, a potential vaccine candidate. Infect Immun 73: 7569-7577. Available from https://doi.org/10.1128/IAI.73.11.7569-7577.2005.

Post DMB, Ketterer MR, Coffin JE, et al. 2016. Comparative analyses of the lipooligosaccharides from nontypeable Haemophilus influenzae and Haemophilus haemolyticus show differences in sialic acid and phosphorylcholine modifications. Infect Immun 84: 765-774. Available from https://doi.org/10.1128/IAI.01185-15.

Qureshi N, Takayama K, Seydel U, et al. 1994. Structural analysis of the lipid A derived from the lipopolysaccharide of Brucella abortus. J Endotoxin Res 1: 137-148. Available from https://doi. org/10.1177/096805199400100303.

Raetz CR. 1990. Biochemistry of endotoxins. Annu Rev Biochem 59: 129-170. Available from https://doi.org/10.1146/annurev. bi.59.070190.001021.

Raetz CRH, Whitfield C. 2002. Lipopolysaccharide endotoxins. Annu Rev Biochem 71: 635-700. Available from https://doi.org/ 10.1146/annurev.biochem.71.110601.135414.

Rau H, Seydel U, Freudenberg M, Weckesser J, Mayer H. 1995. Lipopolysaccharide of the phototrophic bacterium Rhodospirillum fulvum. Syst Appl Microbiol 18: 154-163. Available from https://doi.org/10.1016/S0723-2020(11)80387-5.

Reynolds CM, Kalb SR, Cotter RJ, Raetz CRH. 2005. A phosphoethanolamine transferase specific for the outer 3deoxy-D-manno-octulosonic acid residue of Escherichia coli lipopolysaccharide identification of the eptB gene and $\mathrm{Ca} 2+$ hypersensitivity of an eptB deletion mutant. J Biol Chem 280: 21202-21211. Available from https://doi.org/10.1074/jbc. M500964200.

Richards SM, Strandberg KL, Gunn JS. 2010. Salmonella-regulated lipopolysaccharide modifications. Subcell Biochem 53: 101-122. Available from https://doi.org/10.1007/978-90-481-9078-2_5.

Rietschel ET, Cavaillon J-M. 2003. Richard Pfeiffer and Alexandre Besredka: creators of the concept of endotoxin and anti- 
endotoxin. Microbes Infect 5: 1407-1414. Available from https:// doi.org/10.1016/j.micinf.2003.10.003.

Schweda EKH, Richards JC, Hood DW, Moxon ER. 2007. Expression and structural diversity of the lipopolysaccharide of Haemophilus influenzae: implication in virulence. Int $\mathrm{J}$ Med Microbiol IJMM 297: 297-306. Available from https://doi.org/ 10.1016/j.ijmm.2007.03.007.

Shah NR, Albitar-Nehme S, Kim E, et al. 2013. Minor modifications to the phosphate groups and the $\mathrm{C} 3$ ' acyl chain length of lipid A in two Bordetella pertussis strains, BP338 and 18-323, independently affect Toll-like receptor 4 protein activation. $J$ Biol Chem 288: 11751-11760. Available from https://doi.org/10.1074/jbc. M112.434365.

Sippel JE, Hanafy HM, Diab AS, Prato C, Arroyo R. 1987. Serodiagnosis of typhoid fever in paediatric patients by anti-LPS ELISA. Trans R Soc Trop Med Hyg 81: 1022-1026. Available from https://doi.org/10.1016/0035-9203(87)90386-5.

Sonesson A, Jantzen E, Bryn K, Larsson L, Eng J. 1989. Chemical composition of a lipopolysaccharide from Legionella pneumophila. Arch Microbiol 153: 72-78.

Staub AM, Tinelli R. 1956. Attempted identification of O antigens of Salmonellae by means of periodic oxidation of specific polysaccharides. C R Hebd Seances Acad Sci 243: 1460-1463.

Staub AM, Tinelli R, Luderitz O, Westphal O. 1959.Immunochemical study of Salmonella. V. Role of various sugars, especially 3, 6-bisdesoxyhexoses, in the specificity of Kauffmann-White $\mathrm{O}$ antigens. Ann Inst Pasteur 96: 303-332.

Steeghs L, de Cock H, Evers E, Zomer B, Tommassen J, van der Ley P. 2001. Outer membrane composition of a lipopolysaccharidedeficient Neisseria meningitidis mutant. EMBO J 20: 6937-6945. Available from https://doi.org/10.1093/emboj/20.24.6937.

Steeghs L, den Hartog R, den Boer A, Zomer B, Roholl P, van der Ley P. 1998. Meningitis bacterium is viable without endotoxin. Nature 392: 449-450. Available from https://doi.org/10.1038/33046.

Thursby E, Juge N. 2017. Introduction to the human gut microbiota. Biochem J 474: 1823-1836. Available from https://doi.org/ 10.1042/BCJ20160510.

Townsend S, Caubilla Barron J, Loc-Carrillo C, Forsythe S. 2007. The presence of endotoxin in powdered infant formula milk and the influence of endotoxin and Enterobacter sakazakii on bacterial translocation in the infant rat. Food Microbiol 24: 67-74. Available from https://doi.org/10.1016/j.fm.2006.03.009.
Trent MS. 2004. Biosynthesis, transport, and modification of lipid A. Biochem Cell Biol 82: 71-86. Available from https://doi.org/ 10.1139/o03-070.

Trent MS, Stead CM, Tran AX, Hankins JV. 2006. Diversity of endotoxin and its impact on pathogenesis. J Endotoxin Res 12: 205-223. Available from https://doi.org/10.1179/ $096805106 \times 118825$.

Valvano MA, Furlong SE, Patel KB. Genetics, biosynthesis and assembly of O-Antigen. In Knirel YA, Valvano MA, eds. Bacterial lipopolysaccharides: structure, chemical synthesis, biogenesis and interaction with host cells. Vienna: Springer, 2011, pp. 275-310. Available from https://doi.org/10.1007/978-3-7091-0733-1_9.

Velasco J, Moll H, Knirel YA, Sinnwell V, Moriyón I, Zähringer U. 1998. Structural studies on the lipopolysaccharide from a rough strain of Ochrobactrum anthropi containing a 2, 3-diamino-2, 3dideoxy-D-glucose disaccharide lipid A backbone. Carbohydr Res 306: 283-290.

Wang A, Molina G, Prima VKW, Wang K. 2011. Anti-LPS test strip for the detection of food contaminated with Salmonella and E. coli. J Microb Biochem Technol 03. Available from https://doi. org/10.4172/1948-5948.1000046.

West NP, Sansonetti P, Mounier J, et al. 2005. Optimization of virulence functions through glucosylation of Shigella LPS. Science 307: 1313-1317. Available from https://doi.org/ 10.1126/science.1108472.

Yethon JA, Heinrichs DE, Monteiro MA, Perry MB, Whitfield C. 1998. Involvement of waaY, waaQ, andwaaP in the modification of Escherichia coli lipopolysaccharide and their role in the formation of a stable outer membrane. J Biol Chem 273: 26310 26316. Available from https://doi.org/10.1074/jbc.273.41.26310.

Zähringer U, Knirel YA, Lindner B, et al. 1995. The lipopolysaccharide of Legionella pneumophila serogroup 1 (strain Philadelphia 1): chemical structure and biological significance. Prog Clin Biol Res 392: 113-139.

Zhang-Sun W, Augusto LA, Zhao L, Caroff M. 2015. Desulfovibrio desulfuricans isolates from the gut of a single individual: structural and biological lipid A characterization. FEBS Lett 589: 165-171. Available from https://doi.org/10.1016/j.febslet.2014.11.042.

Zhang-Sun W, Tercé F, Burcelin R, Novikov A, Serino M, Caroff M. 2018. Structure function relationships in the lipids A from Ralstonia species rising in obese patients. Biochimie 159: 72-80. Available from https://doi.org/10.1016/j.biochi.2019.01.015.

Cite this article as: Caroff M, Novikov A. 2020. Lipopolysaccharides: structure, function and bacterial identification. $O C L 27: 31$. 